\title{
Digital product innovation management: Balancing stability and fluidity through formalization
}

\author{
Robin Pesch $^{1}$ (1) | Herbert Endres ${ }^{2}$ | Ricarda B. Bouncken ${ }^{3}$
}

\begin{abstract}
${ }^{1}$ Newcastle University Business School, Newcastle University, Newcastle upon Tyne, UK

${ }^{2}$ Chair of Marketing \& Innovation Management, University of Paderborn, Paderborn, Germany

${ }^{3}$ Chair of Strategic Management and Organisation, University of Bayreuth, Bayreuth, Germany
\end{abstract}

\section{Correspondence}

Herbert Endres, Chair of Marketing \& Innovation Management, University of Paderborn, Paderborn, Germany.

Email: herbert.endres@uni-paderborn.de

\begin{abstract}
While an increasing body of research is considering the role of digital product innovation for firms' survival, there is still a dearth of studies on how firms can best pursue digital product innovations. The development of these innovations is often accompanied by uncertainty and ambiguity. Thus, firms might benefit from the greater clarity and guidance that result from formalization. However, the application of formalized procedures and structures might also lead to the suppression of fluidity, creativity, or change. Therefore, the purpose of this study is to determine if formalization at the project level can enhance digital product innovation. A partial duality logic integrating evidence of both the positive and negative effects of formalization builds the fundament for the hypothesized model. We use survey and patent data for a sample of 395 firms operating in the manufacturing industry to test the model. The results suggest the diminishing marginal utility of formalizationthat is, formalization enhances digital product innovation radicalness and digital product innovation performance but with decreasing positive marginal returns. These findings challenge the widespread assumptions on the relationship between formalization and innovation. This new perspective on the relationship between formalization and innovation helps identify conditions in which formalization can facilitate firms' efforts to develop profitable, innovative digital products. For example, the results demonstrate that older firms in particular can benefit from formalization. In turn, beyond providing insights for executives, this study offers answers to persistent research questions concerning which organizational arrangements are optimal for enhancing digital product innovation.
\end{abstract}

\section{KE Y W O R D S}

age, digitalization, digital innovation, duality, formalization, innovation performance, product innovation management, radicalness

\section{INTRODUCTION}

Digital technologies, such as additive manufacturing, artificial intelligence, cloud computing, data analytics, social media, and wireless sensor networks (Lanzolla et al., 2021; Vial, 2019) offer unparalleled opportunities for developing and delivering novel products (Verganti et al., 2020). For example, monitoring functions in running shoes and watches or 3D printing enables customers to personalize products to an extent that was not possible

This is an open access article under the terms of the Creative Commons Attribution-NonCommercial-NoDerivs License, which permits use and distribution in any medium, provided the original work is properly cited, the use is non-commercial and no modifications or adaptations are made.

(C) 2021 The Authors. Journal of Product Innovation Management published by Wiley Periodicals LLC on behalf of Product Development \& Management Association. 
before (Rindfleisch et al., 2017). Unsurprisingly, firms are increasingly relying on digital product innovation to enhance their performance (Nylén \& Holmström, 2015). Digital product innovations refer to novel products or services embodied in or enabled by digital technologies (Lyytinen et al., 2016; Nambisan et al., 2017).

Despite recognition of the importance of these innovations for firms' survival (Nylén \& Holmström, 2015), little research has addressed which organizational arrangements are appropriate for promoting the development of digital product innovation. Thus, we lack insights into the unique demands of digital product innovation compared with non-digital innovation (Nylén \& Holmström, 2015). In particular, digital product innovation entails an "unprecedented level of unpredictability and dynamism" (Nambisan, et al., 2017, p. 225). The functions and consequences of digital technologies are vague, leading to uncertain innovation potential and value (Matt et al., 2015; Nylén \& Holmström, 2015). Relative to non-digital innovation, digital product innovation tends to be in a greater state of flux. This is mainly the case because different actors (e.g., users, other firms) can readily extend the features, program sequences, scope, and value of digital products after they have been launched (Lyytinen et al., 2016).

These uncertainties about the functionalities and innovation potential of digital technologies result in ambiguous and even conflicting ideas or interpretations during digitalization projects. These projects support the implementation and application of digital technologies to realize the innovation potential of these technologies. To unleash this innovation potential, digitalization projects must resolve ambiguity (Nambisan et al., 2017) and transform project members' fragile and diverse knowledge and interpretations into novel digital products (Bouncken \& Barwinski, 2021; Lyytinen et al., 2016). Therefore, an important question arises about how to coordinate these projects to enhance digital product innovation.

Previous research has culminated in two contrasting views on the notion of formalization, defined as the "extent of written rules, procedures, and instructions" in place (Scott \& Davis, 2006, p. 29). The bureaucratic view suggests that formalization provides stability and promotes effective coordination by specifying role expectations and decision processes (Adler \& Borys, 1996; Briscoe, 2007; Teller et al., 2012). However, the post-bureaucratic view emphasizes the merits of emergent, fluid, ad hoc coordination (Bourgoin et al., 2020; Kellogg et al., 2006). These latter scholars argue that formalization leads to a loss of flexibility because it encourages mindless, rigid adherence to written rules (Mintzberg \& McHugh, 1985).

As a result of these different perspectives, managers lack guidance on two aspects. First, they do not know how

\section{Practitioner points}

- Formalization of digitalization projects can improve the performance and radicalness of digital product innovation.

- Formalization is especially beneficial for digital product innovation in older firms.

- High levels of formalization can be beneficial for digital product innovation even though the merits of additional formalization decrease with increasing formalization.

- Innovation managers can apply formalization to balance stability and flexibility.

to design and coordinate their projects. Second, they have no clear understanding whether formalization in digitalization projects benefits or undermines digital product innovation. Thus, in the light of the stated theoretical and practical importance, the current research aims to address the research question: Does the formalization of digitalization projects facilitate or impede digital product innovation?

To accomplish our research purpose, we adopt a duality logic. Duality implies that two elements are interdependent and complementary, rather than separate or contrasting (Farjoun, 2010). According to this logic, bureaucratic and post-bureaucratic views might function as complements to improve coordination. We hypothesize that the orientation and guidance provided by formalization can complement fluid and emergent coordination efforts to enhance digital product innovation. Precisely, we assume that formalizing the procedures required to build, accomplish, and monitor digitalization projects can have positive effects on digital product innovation performance and digital product innovation radicalness, but the marginal returns might diminish.

Our model proxies digital innovation performance by (a) growth in digital patents and (b) relative digital product innovation performance. Relative performance refers to the profitability, revenues, and general success rate of a firm's digital products compared to its competitors. Referring to previous literature (Garcia \& Calantone, 2002), we define radical digital product innovations as innovations that embody or are enabled by digital technologies and initiate technological or marketing discontinuities at the world, industry, and firm levels.

Our hypothesized model suggests partial duality by assuming non-linear effects that are contextually dependent on firm age. Importantly, firm age contextualizes effects because older firms are more prone to inertia (Coad et al., 2016; Dougherty \& Hardy, 1996). Formalization 


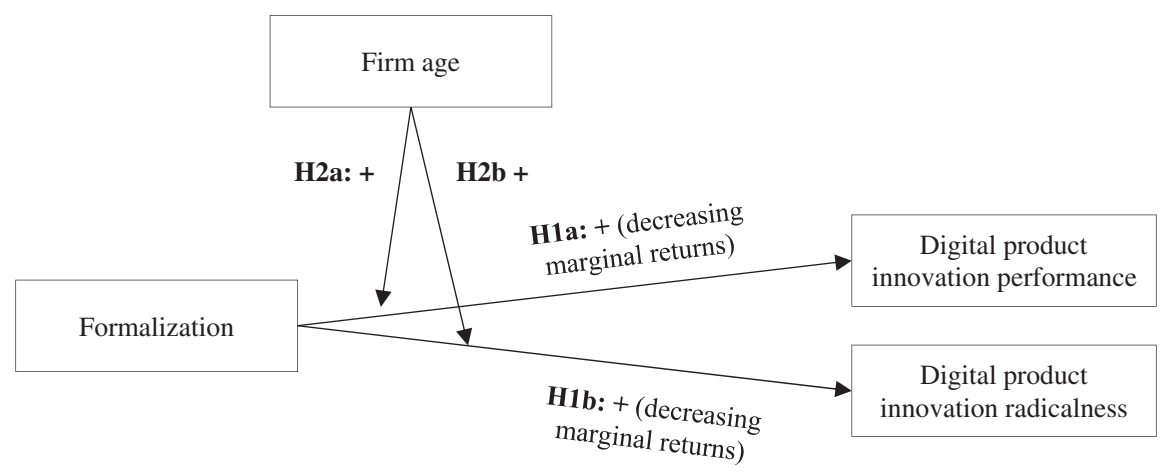

F I G URE 1 Hypothesized model

might guide sensemaking processes to foster rethinking established patterns and, thus, operate as a prerequisite to change and innovation, particularly in older firms. Hence, we hypothesize that older firms can gain more from formalization than younger firms can.

To test our hypothesized model (Figure 1), we draw on a sample of 395 firms operating in the manufacturing industry. The empirical study combines multiple sources including two different databases (Espacenet and Amadeus) and survey data. Our results support the hypothesized diminishing marginal returns of formalization on both digital product innovation performance and radicalness. Moreover, the enabling effects of formalization seem to be limited in younger firms, as our results show a positive moderation effect of firm age.

Our study contributes to literature on digital product innovation by highlighting the intersection of organizational arrangements and digital product innovation (Hopp et al., 2018; Lanzolla et al., 2021; Spanjol et al., 2018; Yoo et al., 2012). We provide answers to the pressing question about which organizational arrangements promote digital product innovation (Appio et al., 2021). In this vein, our findings inform the theoretical debate about formalization as a coordination mechanism in ambiguous, uncertain, and dynamic environments (Christiansen \& Varnes, 2009; Juillerat, 2010; Ramus et al., 2017; Sine et al., 2006).

While previous research has converged on an inverted U-shaped relationship between formalization and performance (Vlaar et al., 2006), our results specify that even high levels of formalization support digital product innovation. Informing the nexus between organization theory and innovation, our study suggests the need to reconsider the prevalent bureaucracy-post-bureaucracy dichotomy (Kellogg et al., 2006) and contributes a duality approach to digital product innovation research.

Finally, our results provide practical recommendations for managers on two major aspects. First, managers who want to promote digital product innovation should think about applying formalization to establish the required stability that assists project members to cope with uncertainty and dynamism. Second, our study shows under which conditions formalization is likely to enhance digital product innovation.

\section{THEORETICAL BACKGROUND}

\subsection{Digital product innovation}

A distinctive element of digital production innovation are digital technologies (Lyytinen et al., 2016), defined as combinations of information, computing, communication, and connectivity technologies (Bharadwaj et al., 2013). Such combinations are 3D printing, artificial intelligence, cloud computing, data analytics, social media, and wireless sensor networks (Loebbecke \& Picot, 2015; Nwankpa \& Datta, 2017). Their application offers unparalleled opportunities for the development and delivery of novel products (Verganti et al., 2020). As defined by Lyytinen and Yoo (2016) digital product innovations are significantly novel products or services that are embodied in or enabled by digital technologies. They might be products for private consumers or for business contexts (Yoo et al., 2012).

Digital product innovation embodied in digital technologies can exist as total or partial digital solutions (Nambisan et al., 2017). Some examples of total digital solutions include new enterprise platforms (business) or video streams (private). Partial digital solutions instead occur when digital technologies complement existing physical products (Kohli \& Melville, 2019), such as running shoes embedded with radio frequency identification chips that can transfer real-time data about the jogger's run to a smartphone, analyze the run, or share it on social media sites (Yoo et al., 2012). Machine monitoring, enabled by Industry 4.0, is a partial digital solution in a business context.

As digital solutions are malleable, editable, open, and transferrable (Yoo et al., 2010), they often remain incomplete and in a state of flux (Nambisan et al., 2017), such that they continue to evolve even after their launch and implementation. Different actors (e.g., users, customers, competitors, firms in other industries) can actively expand 
the scope and scale of digital product innovation (Lyytinen et al., 2016; Nambisan et al., 2017). Consider Google Maps as a case in point. Google initially developed a digital map application for a chosen location, but it sparked a plethora of innovations, such that Google Maps currently is embedded in more than 2300 digital products (Henfridsson et al., 2018). For example, Uber integrated Google Maps into its mobility app, so that riders can see which drivers are in their immediate vicinity. It also links this geographical position information with information about and evaluations of drivers.

Such fluidity is both a key characteristic of digital product innovation and a source of unprecedented unpredictability and uncertainty with regard to their usage and future application possibilities (Nambisan et al., 2017). Beyond those sources of uncertainty, innovation managers might have limited understanding of the functionalities and consequences of digital technologies (Nylén \& Holmström, 2015).

Uncertainty can be classified according to Milliken's (1987) three types: state, effect, or response. In relation to digital technologies, state uncertainty implies an inability to predict how these technologies will affect or change markets, customer behavior, industries, or society in general (Loebbecke \& Picot, 2015). Effect uncertainty describes the inability to predict how changes due to digital technologies are likely to influence the company or its product offerings. Finally, response uncertainty implies a lack of insights into the available means to respond to changes caused by digital technologies and an inability to predict the likely consequences of these responses (Milliken, 1987).

Actors involved in digitalization projects must cope with all three types of uncertainty. Each type can also provoke role ambiguity that relates to discrepancies between position-related information and the information needed to perform a role (Organ \& Greene, 1981). In addition to that digitalization projects often consist of members from different functional backgrounds (Malhotra \& Majchrzak, 2021). The members' diverse goals, motives, and capabilities can cause coordination ambiguities (Nambisan et al., 2017). Project members might be unable to fully and collectively apply digital technologies to develop digital product innovation unless they can coordinate their actions and cope with these types of uncertainties and ambiguities.

\subsection{Contrasting perspectives on formalization}

According to Weber's (1947) description of the ideal bureaucratic type, formalization relates to "the extent of written rules, procedures, and instructions" (Scott \& Davis, 2006, p. 29). Formalization reflects both the outcome and the methods to achieve it (Vlaar et al., 2006) as it includes the process of codifying and enforcing outputs, behaviors, and their outcomes (Ouchi, 1979).

The rational ideal of bureaucracy suggests that formalization can reduce or eliminate uncertainties and ambiguities (Weber, 1947) by guiding individual action and specifying role expectations or decision processes (Adler \& Borys, 1996). Without formalization, role ambiguities and perceived uncertainties are likely to arise, so the bureaucratic logic argues that formalization promotes effective coordination, innovation, and performance (Briscoe, 2007; Cardinal, 2001; Jansen et al., 2006; Juillerat, 2010; Tatikonda \& Montoya-Weiss, 2001; Teller et al., 2012).

A contrasting view suggests that bureaucratic structures have limited value for coping with unforeseeable developments in rapidly changing environments (De Meyer et al., 2002). According to this post-bureaucratic perspective, formalization impedes innovation, flexibility, adaption, and motivation in uncertain, rapidly changing environments (Burns \& Stalker, 1961; Damanpour, 1991; Hannan \& Freeman, 1984; Mintzberg, 1994). It also might force mindless or rigid adherence to documented, codified processes (Mintzberg, 1994), which then limits task autonomy, creativity, change, and experimentation, as it narrows the range of behavior (Jansen et al., 2006; March \& Simon, 1958). Therefore, post-bureaucracy proponents advocate for organizational arrangements that oppose a bureaucratic logic, to enable organizationally fluid responses to environmental dynamism and uncertainty (Dobusch et al., 2019). Organizational fluidity embraces flexibility and rejects strict organizational boundaries, structures, or processes (Kellogg et al., 2006; Schreyögg \& Sydow, 2010). Postbureaucratic scholars advocate radical decentralization and self-organizing systems as appropriate organizational means to ensure organizational fluidity that helps to cope with uncertainties and dynamism (Bourgoin et al., 2020).

As a core coordination mechanism, the post-bureaucracy view relies on heterarchies, which involve interdependence relations and a limited hierarchy, in which people with diverse skills and functional and occupational affiliations work on projects together. Rather than a classical bureaucratic idea of a hierarchy (Kellogg et al., 2006; Schreyögg \& Sydow, 2010) or idealized formalization (Weber, 1947), post-bureaucratic organizations rely more on horizontal relations and improvised, flexible, participative work processes (Kellogg et al., 2006; Martela, 2019) (Table 1).

\subsection{Duality perspective on formalization}

An emerging, still fragmented research stream challenges the post-bureaucratic notion of full fluidity or flexibility and questions the opposition of bureaucratic 
TABLE 1 Bureaucratic logic, post-bureaucratic logic, and duality

\begin{tabular}{|c|c|c|c|}
\hline & Classical bureaucratic logic & Post-bureaucratic logic & Duality \\
\hline Aims & $\begin{array}{l}\text { - Stability and order } \\
\text { - Avoid arbitrariness } \\
\text { - Organizational members } \\
\text { should know how to perform a } \\
\text { task }\end{array}$ & $\begin{array}{l}\text { - Flexibility and fluidity } \\
\text { - Innovation } \\
\text { - Organizational members should } \\
\text { be able to apply their esoteric } \\
\text { knowledge and expertise }\end{array}$ & $\begin{array}{l}\text { - Order and stability that enable } \\
\text { flexibility } \\
\text { - Cross-boundary coordination } \\
\text { - Organizational members should } \\
\text { know how to coordinate and align } \\
\text { different interdependent tasks }\end{array}$ \\
\hline Coordination & $\begin{array}{l}\text { - Hierarchy, centralized decision } \\
\text { making } \\
\text { - Detailed and precise job } \\
\text { descriptions that prescribe how } \\
\text { to complete a specific task } \\
\text { - Routinized, formalized, and } \\
\text { rule-based work processes } \\
\text { - Strict adherence to rules; } \\
\text { sanctions if violations occur }\end{array}$ & $\begin{array}{l}\text { - Heterarchy, decentralized decision- } \\
\text { making, temporary work teams } \\
\text { (projects) } \\
\text { - Dynamic and blurred roles } \\
\text { - Improvised, flexible, participative } \\
\text { work processes }\end{array}$ & $\begin{array}{l}\text { Duality of bureaucratic and } \\
\text { post-bureaucratic coordination } \\
\text { mechanisms } \\
\text { - Decentralized decision-making } \\
\text { and flattened hierarchies but } \\
\text { formalization on the project level } \\
\text { - Clear interaction guidelines and } \\
\text { routines }\end{array}$ \\
\hline
\end{tabular}

and post-bureaucratic logics. With the argument that change can emerge from stability (Farjoun, 2010), scholars highlight the advantages of formalization in postbureaucratic environmental conditions that feature novelty, uncertainty, and rapid change (Dönmez et al., 2016). According to this argument, project members need stability to achieve change, adaptation, and innovation in uncertain, rapidly changing environments (Dönmez et al., 2016).

Formalization can provide appropriate levels of guidance and orientation that in turn enable flexibility and innovation (Dougherty \& Hardy, 1996). It therefore complements post-bureaucratic coordination. Codified, documented procedures act as authoritative texts to compensate for the lack of authority that results from dismantling hierarchical arrangements (Schoeneborn et al., 2018). Moreover, formalization can trigger sensemaking processes, through which members attempt to explain and understand a novel, unclear, or confusing element (Dougherty et al., 2000; Gioia \& Chittipeddi, 1991). Vlaar and van den Bosch (2006) argue that in support of sensemaking, formalization can improve focus, enable deliberation and reflection, and instigate flexible interactions in ambiguous situations.

This perspective recognizes bureaucratic and postbureaucratic logics as a duality rather than as a dualism of opposed and separate views (Farjoun, 2010). The possibility that formalization can enable both stability and fluidity seem alien to the contrasting view. Yet, a duality perspective explicitly embraces the two logics as complementary. Just as a car's brakes enable faster, rather than slower, driving, formalization might be a prerequisite for flexible, creative work (Farjoun, 2010).

\section{3 | HYPOTHESES}

\subsection{Formalization and digital product innovation}

The aforementioned characteristics of digital product innovation suggest the need for both fluid, flexible structures for experimenting with novel ideas and guidance, clarity, and structure. Hence, the duality perspective guides our model on the effects of formalization of digitalization projects on digital product innovation radicalness and digital product innovation performance.

Our reasoning for the formalization-digital product innovation performance-relationship is as follows. Codified and documented procedures are conducive to the human need for stability and role clarity to cope with high levels of uncertainty and fluidity (Vlaar et al., 2006) - characteristic features of digital product innovation (Nambisan et al., 2017). Formalization can establish role clarity, for example, by setting clear expectations of the members involved in the digitalization project (Walsh \& Dewar, 1987). Codified and documented procedures can draw project members' attention to specific, required aspects and thereby prevent issues of low importance from distracting project members (Vlaar et al., 2006; Wynand, 2002). For example, a documented project outline and agenda can be applied to guide project members' attention to current market trends and relevant aspects of digital technologies.

In addition, formalization might instigate and maintain coordination to cope with different assumptions and interpretations in cross-functional projects. Functional units tend to develop distinctive thought worlds (Dougherty, 
1992). Such interpretative systems focus on different aspects (e.g., technologies, markets, customer expectations, innovation potential) and influence how project members make sense of digital technologies and their underlying uncertainties or ambiguities (Orlikowski \& Gash, 1994). Formalization can guide a lingua franca that promotes interaction (Ramus et al., 2017; Wynand, 2002). By establishing specific terms, techniques, and operations, formalization guides sensemaking about digital technologies. This supports collaboration between diverse project members who might have different mindsets, interests, knowledge bases, and vocabularies (Hwang \& Powell, 2009). Codified and documented procedures and the prerequisite processes of creating these formal structures facilitate deliberation and reflection (Vlaar et al., 2006) that guide project members' interpretation of what a technology is and its usefulness for the firm (Kaplan \& Tripsas, 2008). Codifying procedures encourages project members to be clear about the variables and parameters to be considered in developing digital product innovations. Formalization translates tacit and ambiguous knowledge around digital technologies by making it explicit and presenting it in an ordered fashion. For example, codified and documented procedures can contain information that clarifies the functionalities of specific digital technologies. These procedures can also include information about current technology trends or customers' preferences and expectations. The guidance provided through formalization supports learning processes and the development of better and even shared understandings (Vlaar et al., 2006).

Developing profitable digital product innovations that match customers' expectations depends on how project members detect innovation opportunities (Bharadwaj et al., 2013) and how project members share with others and then modify their understandings (Nambisan et al., 2017). Formalization enables project members to address these two aspects. By providing a more comprehensive understanding of digital technologies, innovation potentials, and customers' expectations, formalization enables project members to respond to the fluid and uncertain nature of digital product innovations. This understanding facilitates developing digital product solutions that will be profitable and meet customers' expectations. Therefore, we hypothesize that formalization increases digital product innovation performance.

However, we additionally assume the occurrence of decreasing marginal returns. These specify a logarithmic relationship between formalization and digital product innovation performance. When there is high formalization, the positive effects of additional codification and documentation on digital product innovation performance should be lower than would be the case with low levels of formalization. The formalization at a higher level is already effective in providing clarity and orientation. Thus, project members' perceived uncertainty and ambiguity already are lower. Therefore, the need for further orientation and guidance through even higher formalization decreases at these high formalization levels. Consequently, the enabling effects of additional formalization for digital product innovation performance should be weaker at high levels of formalization.

Hypothesis 1a Formalization has a logarithmic relationship with digital product innovation performance.

Our model proposes that formalization can even foster radicalness rather than restrict it. Radical innovations are seldom an outcome of individual genius. Instead, they reside in collective and formalized approaches to coordinating resources and integrating project members' knowledge and ideas into radical solutions (Farjoun, 2010). In the digital innovation context, scholars highlight fluidity and uncertainty around innovation potentials as specific characteristics and challenges of integrating diverse expertise to develop radical solutions (Henfridsson et al., 2018; Nambisan et al., 2017).

The guidance and orientation afforded by formalization can promote collective coordination under these conditions (Farjoun, 2010). Shared and codified procedures provide a reference point for participants in the sense of reaching and applying a common and basic understanding (Vlaar et al., 2006). This common understanding and guidance, in turn, enable project members to creatively integrate their insights and knowledge into novel and radical solutions. Formalization allows project members to do this without requiring a thorough understanding of digital technologies and the various underlying details specific to each functional area.

Moreover, the orientation and guidance provided by formalization assist project members in coping effectively and efficiently with uncertainties and dynamism. These advantages might unleash temporal and cognitive resources (Juillerat, 2010). By contrast, in the absence of formal procedures, project members must invest more of their cognitive resources and limited time to coordinate dynamic and uncertain project work. They have fewer slack resources to reflect on or experiment with the radical innovation potentials of digital technologies. Thus, formalization can guide energy to detect and realize radical innovation potentials. In line with the logic of diminishing marginal returns applied for Hypothesis 1a, these enabling effects of additional formalization should be weaker at higher levels of formalization.

Hypothesis 1b Formalization has a logarithmic relationship with digital product innovation radicalness. 


\subsection{Contextualization: Firm age as moderator}

Technological changes can particularly challenge firms that have long histories of stable operations because, to implement changes, they must fundamentally transform their business or product portfolios and upend their takenfor-granted logics and structures (Dougherty \& Hardy, 1996). To survive in the digital age, older firms in particular rethink their long-established routines and patterns of doing business (Svahn et al., 2017). Conversely, young firms operate on (still) more fluid and less rigid routines and, today, will have already started their business on the basis of digital product innovations or digital procedures (Bouncken \& Barwinski, 2021; Monaghan et al., 2020). Therefore, we posit that compared to younger firms, older firms will have greater needs for guidance and orientation through formalization for coping with uncertainties related to digital technologies (Svahn et al., 2017).

In addition, older firms' structural capacity to promote flexibility and innovation offers another rationale for considering the moderating influence of firm age when hypothesizing about the effects of formalization. Studies on inertia identify causality between firm age and inertia (Hannan \& Freeman, 1984; Shimizu \& Hitt, 2005). Age tends to rigidify interpretation systems. Thus, older firms likely have developed systems of rules and formalized roles over time, which can lead to "habits of mind" (Shimizu \& Hitt, 2005). These habits leave them more prone to inertia that impedes their flexibility to promote and adjust product innovation in changing technological environments (Hannan \& Freeman, 1984; Majumdar, 1997). In this sense, older firms require specific organizational arrangements to be able to mobilize resources for technological change and innovation as well as to draw attention to and make meaning of the role of digital technologies for innovation (Dougherty \& Hardy, 1996).

In the post-bureaucratic view, formalization is expected to be counterproductive to digital product innovation for older firms because it increases their already high levels of rigidity and promotes bureaucratic ossification. Yet we hypothesize that when pursuing digital product innovation, formalization offers greater benefits for older than for younger firms. As the partial duality perspective suggests, formalization can enhance structural capacity by offering flexible coordination advantages and provide guidance and orientation in uncertain and fluid digital product innovation contexts. In older firms, these functions can support project members in navigating the unfamiliar and uncharted territory of digital technologies. Codified and documented procedures provide relevant contextualization that helps project members cope with specific comprehension problems and uncertainties that arise in older firms due to unfamiliarity with digital product innovation. Younger firms tend to have less need for this guidance or orientation because they are often familiar with digital technologies (Svahn et al., 2017). Consequently, the benefits of formalization for digital product innovation performance might be smaller in younger firms. The dysfunctions of formalization-highlighted by the postbureaucratic view (Kellogg et al., 2006) - might even have the potential to counteract the enabling effects of formalization in younger firms. In other words, younger firms might benefit less from formalization and older firms might benefit more from it.

\section{Hypothesis 2a Firm age positively moderates the relation- ship between formalization and digital product inno- vation performance.}

Previous research argues that inertia and the uncertain payoffs of radical innovations can make older firms, compared to younger firms, more reluctant to promote and experiment with radical digital product solutions (Hill \& Rothaermel, 2003). To minimize uncertainty, older firms will likely seek to maximize returns from known technologies and successful products instead of experimenting with radical solutions (Svahn et al., 2017). In such a climate of aiming at minimizing uncertainty, project members in older firms might be hesitant to follow new pathways and pursue radicalness and might struggle with accessing the required resources for developing radical solutions (Hill \& Rothaermel, 2003). This tendency might particularly account for the fluid digital innovation context (Svahn et al., 2017). We hypothesize that formalization can counteract this tendency.

Formalization supports dealing with some uncertainties that might impede project members in older firms from experimenting with radical digital product innovations (Hill \& Rothaermel, 2003; Svahn et al., 2017). Additionally, formalization can even help project members challenge established innovation practices and overcome resistance to change. Consider the example of codified procedures that urge project members to reflect on radical innovation potentials when building and monitoring the project. In addition, codified and documented procedures might help project members of older firms access and coordinate the resources (Vlaar et al., 2006) they require to go beyond established product portfolios to develop radical digital product innovations (Hill \& Rothaermel, 2003; Svahn et al., 2017).

Hypothesis 2b Firm age positively moderates the relationship between formalization and digital product innovation radicalness. 


\section{\begin{tabular}{l|l}
4 & METHODOLOGY
\end{tabular}}

\section{1 $\quad$ Research setting and data collection}

We conducted a survey of 395 firms operating in the European manufacturing industry and gathered objective digital patent data from the European Patent Office (Espacenet) and firm size and age data from the Amadeus database (Bureau van Dijk, Moody's Analytics). Our sample includes firms from the plastics and rubber (35.2\%), utility vehicle (27.7\%), machinery and plant engineering (23.9\%), and energy (13.2\%) industries. Our focus on the manufacturing industry acknowledges the vast digital product innovation potential in these sectors (Cabanes et al., 2019; Ivanov, 2020). For example, interconnected factories, relying on the Internet of Things and Industry 4.0, create opportunities for various digital product innovations, especially in the machinery and plant engineering and the plastics and rubber industry (Baur \& Wee, 2015; Endres et al., 2019; Lange, 2017). Developments involving connected vehicles are prominent in the utility vehicle industry (Heid et al., 2018), and in the energy sector, digital technologies suggest the potential for smart grids (Munuera, 2020). Furthermore, to ensure their competitiveness in the digital age, manufacturing firms likely need to transform their processes and products (Baur \& Wee, 2015). Therefore, members of digitalization project teams working in manufacturing industries likely need guidance and orientation to cope with the uncertainties and dynamism inherent to digital product innovation.

To collect survey data, eight research assistants visited six global manufacturing trade fairs to identify key informants involved in digitalization projects and willing to participate in our paper-and-pencil survey. Before we sent the research assistants to these trade fairs, we randomly selected companies in the represented industries for them to approach. Because trade fairs bring managers from a specific industry together, they offer good opportunities for making contacts (Pesch \& Bouncken, 2017); the six trade fairs we visited featured more than 14,000 exhibitor firms from around the world, from which the teams randomly contacted 1400 firms. The research assistants had the opportunity to explain the research project. We promised a result report to the survey participants to increase their participation willingness.

A total of 457 firms agreed to participate, but only 395 of the informants approached rated themselves as highly informed about digital technologies and digital product innovations in their firms. We chose to exclude the 62 participants who rated themselves as having limited information. Thus, the final sample of 395 firms represents a net response rate of $28.21 \%$, which compares favorably with prior publications (e.g., Chadwick et al., 2015; Flores et al., 2012) and exceeds conventional recommendations for advanced statistical analyses (MacCallum et al., 1999). These key informants are senior managers, who had worked for an average of 8.1 years for their current firm. The sample includes CEOs (19\%), marketing and sales directors (10\%), marketing and product managers (12\%), business development managers (33\%), innovation and technology managers (7\%), operation/process managers (8\%), and others $(11 \%)$. The surveyed firms earned an average of 723 million Euros (median 12 million Euros; standard deviation 5475 ) in revenue and had an average of 2700 employees (median 65; standard deviation 19,733).

\section{2 $\mid$ Measurement}

To measure the constructs, we use reflective multiitems and 5-point Likert-type scales, which we list in the Appendix A. Furthermore, to capture digital product innovation performance, we include objective patent data from the European Patent Office.

Inspired by Zmud (1982), we measure the formalization of digitalization projects by applying three items: (1) core processes to build digitalization projects are strongly formalized within our company, (2) core processes to accomplish digitalization projects are strongly formalized within our company, and (3) core processes to monitor digitalization projects are strongly formalized within our company. As suggested by Haans and Pieters (2016), if the true relationship might be merely one half of a U-shape, we log-transformed this formalization construct to test the hypothesized diminishing marginal utility effect (Dhanaraj \& Beamish, 2004; Moore et al., 2021).

For digital product innovation radicalness, we adapt Bouncken and Kraus's (2013) scale to a digital context. At the beginning of the survey, we presented informants with a precise definition of digital products, in line with the definition we cited previously (Lyytinen et al., 2016). Regarding product innovation performance, we adopt two measures: relative digital product innovation performance and digital patent growth. For the former measure, we rely on the relative competitive performance measure proposed by Deshpandé et al. (1993) and asked the key informants to evaluate their firm's digital product innovations in terms of their success rate, revenues, and profitability in comparison with their competitors'. These items are direct indicators that primarily measure digital product innovation performance; we complement them with digital patent growth as an indirect measure (Dziallas \& Blind, 2019). It captures the rate of change in digital patents each 
firm had registered in the period ranging from the year of the survey to the third year after the survey. We gathered the number of digital patents from the European Patent Office's database (Espacenet), which contains a systematized listing of all cooperative patent classification (CPC) codes related to digital product innovations (Ménière et al., 2017). This classification consists of 321 different CPC codes.

To check the reliability and validity of our latent constructs, we conducted a confirmatory factor analysis (comparative fit index $>0.95$; Tucker-Lewis index $>0.95$; root mean square error of approximation $<0.04)$. Then, we calculated the composite reliability, average variance extracted (AVE), and Fornell-Larcker criterion to validate our reflective constructs. The composite reliability for our latent constructs was greater than 0.70 . The convergent validity was also adequate, because the AVE exceeded 0.50 for each construct (Bagozzi \& Yi, 2012). The results indicated adequate discriminant validity, in that the AVE of each construct exceeded the squared correlation between all pairs of constructs for the same model (Fornell \& Larcker, 1981).

In line with prior research on innovation performance, we included R\&D expenditures, firm size, and industry as control variables (e.g., Dul \& Ceylan, 2014). We measured firm age as the log of the number of years since the establishment of the company; firm size is the log of the number of employees. For R\&D expenditures, we used the share of such expenditures relative to total sales. We added dummy variables for each industry, coded as equal to 2 if that industry was applicable, and 1 otherwise. Table 2 contains the descriptive statistics and intercorrelations.

\section{$5 \mid$ RESULTS}

\subsection{Hypotheses testing}

To test $\mathrm{H} 1$ and $\mathrm{H} 2$, we applied a four-step (Models 1-4) ordinary least squares regression analysis in SPSS 25.0 for our complex model, including a two-way interaction (Cohen et al., 2003). We mean-centered all predictors before creating the interaction terms (Aiken \& West, 1991). Table 3 presents the results for relative digital product innovation performance based on survey data and Table 4 offers the results for digital patent growth. Table 5 shows the results for digital product innovation radicalness.

As the $R^{2}$ values show, the main effects of the formalization in our study accounted for about 24\% (Table 3) of the variance for relative digital product innovation performance, about $10 \%$ (Table 4 ) of the variance for digital patent growth, and about $21 \%$ (Table 5) of the variance for digital product innovation radicalness (Model 2). We find strong, significant, positive influences of (logarithmic) formalization on digital product innovation performance, measured as both relative digital product innovation performance (Table 3, Model 2: $\beta=.498 ; p<.01$ ) and digital patent growth (Table 4, Model 2: $\beta=.330 ; p<.05$ ) in support of H1a. The results also support H1b. The relationship between (logarithmic) formalization and digital product innovation radicalness is significant and positive (Table 5, Model 2: $\beta=.477 ; p<.01$ ).

We also find a positive moderating effect of firm age on the relationship between formalization and relative digital product innovation performance (Table 3, Model 4: $\beta=.068 ; p<.10)$ and between formalization and digital

TA B LE 2 Descriptive statistics and interitem correlations

\begin{tabular}{|c|c|c|c|c|c|c|c|c|c|c|c|}
\hline Variables & 1 & 2 & 3 & 4 & 5 & 6 & 7 & 8 & 9 & 10 & 11 \\
\hline 1. Formalization & 1.00 & & & & & & & & & & \\
\hline 2. Firm age & .04 & 1.00 & & & & & & & & & \\
\hline 3. Firm size & .13 & .30 & 1.00 & & & & & & & & \\
\hline $\begin{array}{l}\text { 4. Relative digital production innovation } \\
\text { performance }\end{array}$ & .48 & -.11 & -.04 & 1.00 & & & & & & & \\
\hline 5. Digital patent growth & .35 & -.06 & -.02 & .02 & 1.00 & & & & & & \\
\hline 6. Digital product innovation radicalness & .47 & -.11 & -.01 & .81 & .03 & 1.00 & & & & & \\
\hline 7. Machinery engineering & .12 & -.02 & -.16 & .08 & .16 & .07 & 1.00 & & & & \\
\hline 8. Utility vehicle industry & .02 & .09 & .23 & -.07 & -.17 & -.02 & -.32 & 1.00 & & & \\
\hline 9. Plastics and rubber industry & -.15 & .06 & -.02 & -.07 & -.19 & -.09 & -.38 & -.42 & 1.00 & & \\
\hline 10. Energy industry & .02 & -.02 & .09 & .02 & .20 & .00 & -.20 & -.22 & -.27 & 1.00 & \\
\hline 11. R\&D expenditures & .03 & .06 & -.13 & .05 & -.14 & .05 & .06 & -.11 & -.05 & -.02 & 1.00 \\
\hline Mean & .32 & 1.55 & 1.90 & 2.98 & .42 & 3.07 & 1.23 & 1.26 & 1.33 & 1.12 & 16.58 \\
\hline Standard deviation & .24 & .69 & .91 & 1.08 & .41 & 1.09 & .42 & .44 & .47 & .33 & 12.11 \\
\hline
\end{tabular}

Note: Significant correlations ( $p$-value $<.05$ are in bold; two-tailed). 
T A B L E 3 Standardized ordinary least square regression results for relative digital product innovation performance $(N=395)$

\begin{tabular}{|c|c|c|c|c|c|c|c|c|}
\hline & \multicolumn{8}{|c|}{ Dependent variable: Relative digital product innovation performance } \\
\hline & \multicolumn{2}{|c|}{$\begin{array}{l}\text { Model } 1 \text { (controls } \\
\text { only) }\end{array}$} & \multicolumn{2}{|c|}{$\begin{array}{l}\text { Model } 2 \text { (with main } \\
\text { effect) }\end{array}$} & \multicolumn{2}{|c|}{$\begin{array}{l}\text { Model } 3 \text { (with direct } \\
\text { effect of moderator } \\
\text { variable) }\end{array}$} & \multicolumn{2}{|c|}{$\begin{array}{l}\text { Model } 4 \text { (with two- } \\
\text { way interaction) }\end{array}$} \\
\hline & $\beta$ & $p$-values & $\beta$ & $p$-values & $\beta$ & $p$-values & $\beta$ & $p$-values \\
\hline \multicolumn{9}{|l|}{ Main effect } \\
\hline Log formalization $(F)$ & & & .498 & .000 & .494 & .000 & .497 & .000 \\
\hline \multicolumn{9}{|l|}{ Direct moderator effect } \\
\hline Firm Age (FA) & & & & & -.118 & .035 & -.119 & .033 \\
\hline \multicolumn{9}{|c|}{ Two-way interaction effect } \\
\hline $\mathrm{FA} \times \mathrm{F}$ & & & & & & & .068 & .090 \\
\hline \multicolumn{9}{|l|}{ Control variables } \\
\hline $\begin{array}{l}\text { Machinery and plant } \\
\text { engineering }\end{array}$ & -.101 & .425 & -.097 & .384 & -.048 & .673 & -.033 & .769 \\
\hline $\begin{array}{l}\text { Utility vehicle } \\
\text { industry }\end{array}$ & -.203 & .133 & -.121 & .305 & -.070 & .561 & -.067 & .574 \\
\hline $\begin{array}{l}\text { Plastics and rubber } \\
\text { industry }\end{array}$ & -.254 & .079 & -.121 & .340 & -.056 & .664 & -.050 & .700 \\
\hline Energy industry & -.163 & .094 & -.080 & .347 & -.060 & .483 & -.057 & .507 \\
\hline Firm size & .000 & .998 & -.084 & .119 & -.045 & .427 & -.045 & .422 \\
\hline R\&D expenditures & .018 & .760 & .014 & .784 & .040 & .454 & .038 & .470 \\
\hline$R^{2}$ & .02 & & & .26 & .27 & & .27 & \\
\hline$\Delta R^{2}$ & - & & .24 & & .01 & & .00 & \\
\hline
\end{tabular}

Note: One-tailed significance for hypothesized relations, and two-tailed significance for controls.

product innovation radicalness (Table 5, Model 4: $\beta=.092$; $p<.05)$. We explore this two-way interaction using the simple slope of formalization at one standard deviation above and below the means of firm age; as Figure 2 indicates, the beneficial effect of formalization is greater for older firms.

\section{\begin{tabular}{l|l}
5.2 & Robustness tests
\end{tabular}}

\subsubsection{Common method bias}

Common method variance can bias the relationships of variables measured with self-reports. Even if the problem of common method variance may be exaggerated (Schaller et al., 2015), we acknowledge that our statistical conclusions may be biased. To minimize the risk of common method bias, as explained previously, we collected data from different sources. The patent data, as complements to our survey data, affirm the hypothesized diminishing marginal utility effect of formalization. Furthermore, we collected additional data from other key informants, representing a subsample of 85 firms, regarding relative digital innovation performance. When we replace responses from the first key informants with the second key informants' responses, we again find a logarithmic relationship between formalization and digital innovation performance $(\beta=.410 ; p=.001)$. Furthermore, we formulated the questions in our survey precisely and separated questions about the dependent variables from those pertaining to the independent variables. We guaranteed the respondents anonymity. With a pretest, we ensured the comprehensibility of the questions, before conducting the survey. Because our analysis includes moderating effects, the potential bias due to respondents' implicit theories is naturally lower (Siemsen et al., 2010). Finally, we employed a marker variable approach to detect common method bias (Lindell \& Whitney, 2001), and the results indicate that it is not a serious concern for our study.

\subsection{2 | Validating the logarithmic formalization effect}

Some prior research predicts that formalization may be beneficial only up to a specific point, after which it becomes destructive (Vlaar et al., 2006). Therefore, we tested 
for an inverted U-shaped effect by calculating the squared effect of formalization on digital product innovation radicalness and both measures of digital product innovation performance, in a post hoc analysis. The insignificant squared effects $(p>.10)$ do not support for the notion of a curvilinear relationship with formalization.

\subsection{3 | Differences between digital-driven versus digital-centric firms}

The effect of formalization might vary across firms which might rely more or less on digital products, such that these products account for a high (digital-centric) or low (digital-driven) share of total product sales. Digital-centric firms might have less need for formalization, because they likely have developed strong knowledge and experience about digital technologies and products, relative to digital-driven firms. In a post hoc test, we add the share of digital products as a moderator in the regression analysis. The results indicate a significant negative interaction effect of the share of digital products with formalization, for both relative digital product innovation performance $(\beta=-.18, p=.03)$ and digital product innovation radicalness $(\beta=-21, p=.01)$. The formalization effect remains high $(\beta=.50, p=.00 ; \beta=.54, p=.00)$. That is, the effect of formalization appears to diminish when the share of digital products as a proportion of total sales is higher.

We also tested whether the combination of firm age and share of digital products might influence the relationship between formalization and digital product innovation performance and radicalness. Thus, we calculated a three-way interaction effect of formalization, firm age, and the share of digital products. However, the three-way interaction effect is insignificant $(p>.10)$.

\subsection{4 | Testing different kinds of digital technologies}

The effects of formalization might vary for firms with different technology foci. We asked the survey respondents to specify the digital technologies their digitalization projects employed. The top-five most specified technologies were wireless sensor connectivity technologies, cloud computing, big data analytics, 3D printing, and digital communication technologies. To examine the robustness of the diminishing marginal utility effects of formalization, we tested moderating effects of the five digital technologies by creating dummy modules for each technology. We did not find significant moderating effects of the different technologies on the relationship between formalization and digital patent growth, but differences arose for digital product innovation radicalness and relative digital product innovation performance. For relative digital product innovation performance, we find that firms with a focus on 3D printing profit less from formalization (moderating effect $\beta=-.17, p<.01)$. Regarding digital product innovation radicalness, firms that focus on digital communication technologies (moderating effect: $\beta=.14, p<.05$ ) achieve greater innovation benefits from formalization, but this moderating effect is significantly negative for firms that rely on big data analytics $(\beta=-.16, p<.05)$. Compared with digital communication technologies, 3D printing and big data analytics can be classified as more complex, such that they are characterized by high uncertainty in terms of their potential for product innovation and the value that might be realized (Cappa et al., 2020; Rindfleisch et al., 2017). The results indicate that formalization improves digital product innovation even when it entails more complex digital technologies, though the merits of formalization might be weaker for such digital technologies.

\section{DISCUSSION}

Ambiguity surrounding whether formalization assists digital product innovation or not motivated this study. We propose a partial duality logic that hypothesizes a nonlinear effect of formalization - precisely a positive effect with decreasing marginal returns. To gain a more nuanced understanding, we include firm age as a contingency factor, in line with the general prediction that formalization is subject to contingencies (Ramus et al., 2017; Sine et al., 2006). As our study demonstrates, older firms achieve greater advantages from formalization than younger firms (Figure 2), which aligns with innovation research that indicates that mature firms are more prone to inertia (Hannan \& Freeman, 1984; Shimizu \& Hitt, 2005) and have higher needs for orientation, guidance, and cross-boundary coordination (Dougherty \& Hardy, 1996). This nuanced view challenges the post-bureaucratic logic that alleges formalization leads to habits of mind, especially in older firms. That is, we argue that formalization offers a means to challenge rigid routines and interpretative structures.

Our post hoc analyses provide further insights on contingency factors and support the idea of a partial duality. The positive nonlinear effect of formalization can vary across digital technologies, such that the merits of formalization seem to be lower for more complex, evolving digital technologies. More detailed technology features also might inform the limits of formalization. For example, perhaps firms find it more challenging to develop codified and documented procedures for digitalization projects that include complex digital technologies such as 3D printing. Even though we find some effects of the type of 
T A B L E 4 Standardized ordinary least square regression results for digital patent growth $(N=395)$

\begin{tabular}{|c|c|c|c|c|c|c|c|c|}
\hline & \multicolumn{8}{|c|}{ Dependent variable: Digital patent growth } \\
\hline & \multicolumn{2}{|c|}{$\begin{array}{l}\text { Model } 1 \\
\text { (controls only) }\end{array}$} & \multicolumn{2}{|c|}{$\begin{array}{l}\text { Model } 2 \\
\text { (with main effect) }\end{array}$} & \multicolumn{2}{|c|}{$\begin{array}{l}\text { Model } 3 \text { (with direct } \\
\text { effect of moderator } \\
\text { variable) }\end{array}$} & \multicolumn{2}{|c|}{$\begin{array}{l}\text { Model } 4 \text { (with two- } \\
\text { way interaction) }\end{array}$} \\
\hline & $\beta$ & $p$-values & $\beta$ & $p$-values & $\beta$ & $p$-values & $\beta$ & $p$-values \\
\hline Log formalization $(F)$ & & & .330 & .029 & .330 & .032 & .330 & .033 \\
\hline \multicolumn{9}{|l|}{ Direct moderator effect } \\
\hline Firm age (FA) & & & & & .009 & .960 & -.008 & .965 \\
\hline \multicolumn{9}{|l|}{ Two-way interaction effect } \\
\hline $\mathrm{FA} \times \mathrm{F}$ & & & & & & & .132 & .222 \\
\hline $\begin{array}{l}\text { Machinery and plant } \\
\text { engineering }\end{array}$ & -.157 & .647 & -.159 & .627 & -.162 & .632 & -.137 & .690 \\
\hline Utility vehicle industry & -.454 & .227 & -.411 & .252 & -.415 & .265 & -.402 & .284 \\
\hline Plastics and rubber industry & -.470 & .223 & -.396 & .283 & -.400 & .297 & -.386 & .318 \\
\hline Energy industry & -.061 & .839 & -.033 & .908 & -.035 & .905 & -.035 & .906 \\
\hline Firm size & .026 & .888 & -.028 & .872 & -.031 & .869 & -.028 & .881 \\
\hline R\&D expenditures & -.206 & .254 & -.214 & .215 & -.215 & .226 & -.214 & .231 \\
\hline$R^{2}$ & .16 & & .26 & & .26 & & .28 & \\
\hline$\Delta R^{2}$ & - & & .10 & & .00 & & .02 & \\
\hline$F$-change & - & & 3.910( & & $.003(.96)$ & & $.603(.44)$ & \\
\hline
\end{tabular}

Note: One-tailed significance for hypothesized relations, and two-tailed significance for controls.

technology, our overall findings affirm that formalization can be applied to achieve benefits for digital product innovation across digital technologies that vary in complexity.

\section{1 | Theoretical contribution}

This study responds to recent calls on identifying the organizational arrangements required to promote digital product innovation (Appio et al., 2021). In addition, by introducing the partial duality perspective on formalization, it addresses the long-term conflict of different schools of thoughts between bureaucracy (e.g., Weber, 1947) and post-bureaucracy views (e.g., Kellogg et al., 2006; Mintzberg, 1994). Finally, our finding of decreasing marginal returns introduces novel insights into the discussion of (nonlinear) effects of formalization for innovation. We discuss each of these three contributions in turn.

\subsection{1 | Organizational arrangements to promote digital product innovation}

Research on digital product innovation is in an embryonic stage (Appio et al., 2021). Scholars highlight that digital product innovations have distinctive characteristics compared to non-digital product innovations and cite the importance of these innovations for companies' survival (Nambisan et al., 2017). However, we still know little about how to promote digital product innovation.

This study contributes to emerging research at the intersection of digital product innovation and organizational arrangements (Fichman et al., 2014; Hopp et al., 2018; Lanzolla et al., 2021; Yoo et al., 2012), by demonstrating that the formalization of digitalization projects can enhance digital product innovation. By following the partial duality perspective, we argue that formalization can provide the orientation and guidance that is required for creative and flexible project work. The partial duality perspective enriches research into alternative organizational arrangements for digital product innovation that can balance stability and flexibility (Svahn et al., 2017). Nambisan et al. (2017) call for research into how sociocognitive frames of digital innovations emerge and get shared among different actors. Our study provides first insights by researching formalization as a means that supports to align and challenge project members different interpretations and assumptions of digital technologies for increasing creativity and innovation potentials. Furthermore, this study contributes to discussions of 
T A B L E 5 Standardized ordinary least square regression results for digital product innovation radicalness $(N=395)$

\begin{tabular}{|c|c|c|c|c|c|c|c|c|}
\hline & \multicolumn{8}{|c|}{ Dependent variable: Digital product innovation radicalness } \\
\hline & \multicolumn{2}{|c|}{$\begin{array}{l}\text { Model } 1 \\
\text { (controls only) }\end{array}$} & \multicolumn{2}{|c|}{$\begin{array}{l}\text { Model } 2 \\
\text { (with main effect) }\end{array}$} & \multicolumn{2}{|c|}{$\begin{array}{l}\text { Model } 3 \text { (with direct } \\
\text { effect of moderator } \\
\text { variable) }\end{array}$} & \multicolumn{2}{|c|}{$\begin{array}{l}\text { Model } 4 \text { (with two- } \\
\text { way interaction) }\end{array}$} \\
\hline & $\beta$ & $p$-values & $\beta$ & $p$-values & $\beta$ & $p$-values & $\beta$ & $p$-values \\
\hline Log formalization $(\mathrm{F})$ & & & .477 & .000 & .474 & .000 & .479 & .000 \\
\hline \multicolumn{9}{|l|}{ Direct moderator effect } \\
\hline Firm Age (FA) & & & & & -.099 & .081 & -.101 & .075 \\
\hline \multicolumn{9}{|l|}{ Two-way interaction effect } \\
\hline $\mathrm{FA} \times \mathrm{F}$ & & & & & & & .092 & .037 \\
\hline $\begin{array}{l}\text { Machinery and plant } \\
\text { engineering }\end{array}$ & -.069 & .588 & -.064 & .568 & -.023 & .841 & -.004 & .974 \\
\hline Utility vehicle industry & -.120 & .375 & -.042 & .727 & .002 & .990 & .005 & .969 \\
\hline Plastics and rubber industry & -.220 & .128 & -.093 & .471 & -.038 & .772 & -.029 & .823 \\
\hline Energy industry & -.156 & .108 & -.077 & .372 & -.060 & .489 & -.056 & .521 \\
\hline Firm size & .029 & .635 & -.052 & .340 & -.019 & .739 & -.020 & .731 \\
\hline R\&D expenditures & .004 & .948 & .000 & .998 & .022 & .689 & .020 & .714 \\
\hline$R^{2}$ & .02 & & .24 & & .24 & & .25 & \\
\hline$\Delta R^{2}$ & - & & .21 & & .01 & & .01 & \\
\hline$F$-change & - & & 82.898 & & 3.075 & & 3.216 & \\
\hline
\end{tabular}

Note: One-tailed significance for hypothesized relations and two-tailed significance for controls.
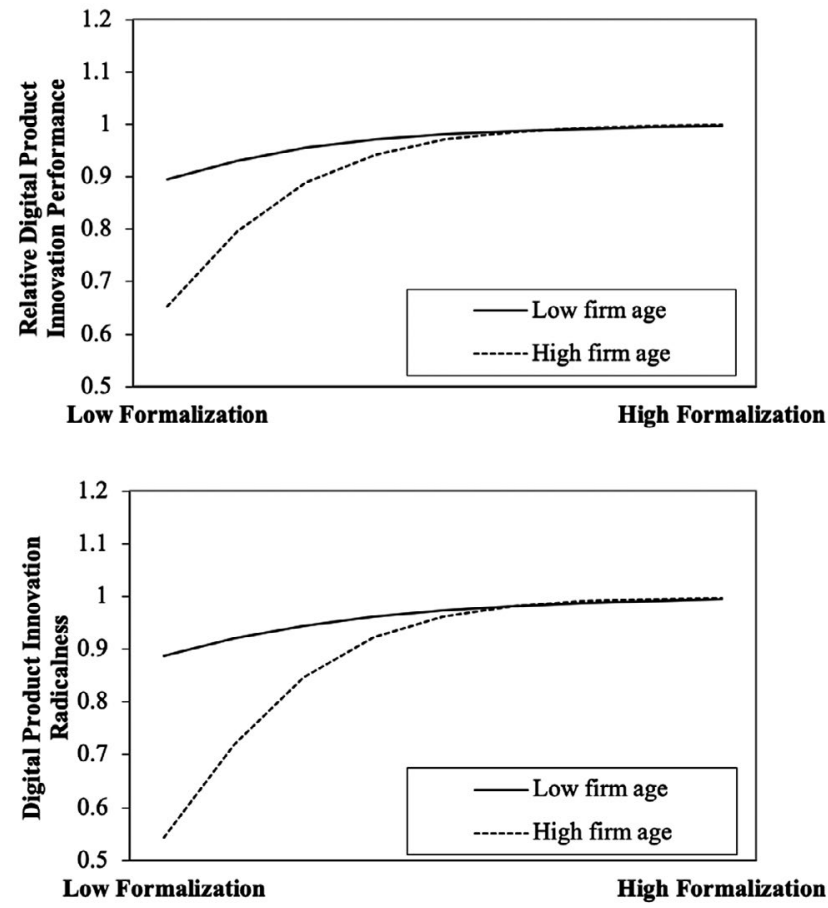

F I G URE 2 Effect of formalization at low and high firm age effective organizational arrangements that can support the integration and transformation of various project members' diverse interpretations about digital technologies into novel digital products (Appio et al., 2021).

\subsection{2 | Partial duality perspective on formalization}

Instead of the merits of formalization, post-bureaucratic proponents emphasize the importance of fluid organizational arrangements to ensure sufficient flexibility that promotes digital product innovations. Yet, discussions of fluid organizational structures often appear to radicalize the principle of organizational flexibility (Schreyögg \& Sydow, 2010). Previous research highlights that organizational functioning requires a balance between stability and fluidity (Aroles \& McLean, 2016; Dönmez et al., 2016).

We argue that the difference between bureaucracy and post-bureaucracy is not a matter of principle but of degree. Formalization may seem alien to a post-bureaucratic world, but formalization can help organizations cope with 
post-bureaucratic environmental conditions. While formalization in the sense of precise descriptions of how to perform and complete a specific task might be difficult, due to the uncertainty and dynamism that surrounds digital technologies and their innovation potentials, formalization at a higher level (Loch et al., 2006), such as the project coordination level, can enable flexible and creative interaction by providing orientation and guidance (Farjoun, 2010; Vlaar et al., 2006).

This study thus offers a new, partial duality perspective that highlights a complementary relation between the bureaucratic and post-bureaucratic logics. This perspective enriches emerging research on alternative organizational arrangements that can balance stability and fluidity in the specific context of digital product innovation (Svahn et al., 2017), as well as in uncertain and rapidly changing environments in general (Aroles \& McLean, 2016; Farjoun, 2010; Schreyögg \& Sydow, 2010).

\subsection{3 | Marginal utility effects of formalization}

Previous innovation research cites the bright side of formalization for innovation (Cardinal, 2001; Jansen et al., 2006; Schultz et al., 2013; Tatikonda \& Montoya-Weiss, 2001) but also its dark side (Burns \& Stalker, 1961; Damanpour, 1991; Jansen et al., 2006; March \& Simon, 1958; Mintzberg, 1994). Some scholars suggest inverted U-shaped effects of formalization (Vlaar et al., 2006), as an option to integrate these two perspectives. According to that argument, medium levels of formalization would offer the greatest merit, relative to low and high levels, where formalization even might have destructive effects.

In contrast, the partial duality logic challenges this underlying opposition, because formalization can enable flexibility and innovation (especially for older firms) by providing necessary guidance and orientation. Instead of positive, negative, or inverted U-shaped relationship, we show that high levels of formalization can offer the greatest benefits for digital product innovation, but the marginal returns are declining. Decreasing marginal returns represent a novel theoretical approach to the effects of formalization. As these findings relate to the specific context of digital product innovation, continued research might explore whether formalization also reveals positive decreasing marginal returns in nondigital innovation contexts, especially very uncertain settings.

\section{2 | Practical implications}

The results of our study provide managerial implications, in line with calls for innovation management research that provides value to business practice (Noble \& Spanjol, 2019). In general, our study shows that firms do not need to worry about avoiding formalization in their digitalization projects. This stands in contrast with a widespread assumption that formalization might create barriers to digital product innovation by impeding creativity and change. Our findings offer a more nuanced perspective that change and innovation are not possible without some degree of stability (Christiansen \& Varnes, 2009; Farjoun, 2010). Managers who want to promote digital product innovation should apply formalization to establish the required stability that project members need to cope with inherent uncertainty and dynamism. We can break this general managerial implication into five specific instructions for action.

First, managers and firms might establish clear roles and make role expectations explicit for members involved in digitalization projects. In the absence of formal structures, project members struggle with uncertainties related to digital product innovations. They have trouble coordinating digital innovation actions and accessing the required organizational resources to advance digital product innovation initiatives. Project members should know how to coordinate and align different interdependent innovation tasks under these conditions. For example, cross-functional interaction difficulties might be mitigated by simply codifying procedures to coordinate interdependent activities.

Second, innovation managers might use formalization to guide employees' information processing (Vlaar et al., 2006). Codified and documented procedures can focus project members' attention on the importance of digital product innovation. Take, for example, codified and documented procedures that encourage or even ask project members to apply their cognitive resources and organizational resources to develop digital product innovations.

Third, managers can utilize formalization to increase digital product innovation radicalness. The orientation and guidance provided by formalization helps project members to creatively integrate their different knowledge and to deal more efficiently with the uncertainties and dynamism. These efficiency advantages might unleash temporal and cognitive resources that project members need to reflect or experiment on digital technologies' radical innovation potentials and their consequences for the firm. Thus, innovation managers need not be concerned that the formalization of digitalization projects will occur at the expense of radicalness.

Fourth, the logarithmic effect of formalization that we show might encourage managers to consider how to formalize their digitalization projects up to a certain point to remain efficient. Even if additional benefits of formalization persist at high levels of formalization, the overall 
increase in digital innovation performance will be limited at these high levels. As creating guidelines and monitoring adherence to them tie up time and resources, additional formalization might be no longer worthwhile beyond a certain point.

Fifth, managers of older firms should adopt formalization more intensively than managers of younger firms because older firms have higher needs for enabling the effects of formalization.

Our findings regarding the control variables reveal further managerial implications. The control variables pertaining to firm size and manufacturing industry sector did not affect the examined outcome variables substantially. We might, therefore, assume that the impact of formalization of digitalization projects on digital product innovation radicalness/performance is neither firm size-specific nor industry-specific across different manufacturing sectors. Thus, managers in various industries and companies of different sizes might think of using formalization to increase both their company's digital product innovation radicalness and digital product innovation performance.

\section{3 | Limitations and avenues for research}

Our sample consists of firms from the manufacturing industry, which may limit generalization of our results. Therefore, continued research should test the robustness of our findings in other industries. Furthermore, previous research distinguishes formalization of goals and targets versus procedures to achieve these targets (Katz \& Kahn, 1966). We concentrate on the formalization of digitalization projects, that is, the procedures instead of the goals and targets. Tests involving other formalization objectives might reveal how different kinds of formalization interact. For example, formalizing precise digitalization goals might promote a clear orientation and support employees' sensemaking. In that case, the question that arises is whether different types of formalization have complementary, substitutive, or contrary effects. Another interesting avenue for research might address how firms implement and communicate their codified and documented procedures to employees. Employees need to understand and be able to apply the procedures; what elements are necessary to develop and formulate procedures that reduce ambiguity rather than creating more of it, through formalization? Building on such considerations, further research also could determine how to develop appropriate formalization mechanisms.

Finally, we address formalization as an organizational means to promote digital product innovation, but emerging research also theorizes about how digital technologies might be applied to improve work or promote collaboration and innovation (Endres et al., 2021; Huesig \& Endres, 2019; Lanzolla et al., 2021; Marion \& Fixson, 2021; Verganti et al., 2020). In turn, researchers might address the extent to which digital technologies themselves can become means to promote and organize new product development efforts.

\section{ACKNOWLEDGMENTS}

The authors thank the editors and the three anonymous reviewers for their helpful feedback and comments. We also thank the participants of the Innovation and Product Development Management Conference (IPDMC) 2020 and Dovev Lavie for their valuable comments on earlier versions of our manuscript. Open access funding enabled and organized by ProjektDEAL.

\section{FUNDING INFORMATION}

The authors have not recieved any funding for this study.

\section{CONFLICT OF INTEREST}

None.

\section{ETHICS STATEMENT}

The authors have conducted the research in full compliance with the journals ethical standards and Committee on Publication Ethics (COPE) international standards for authors.

\section{ORCID}

Robin Pesch (10 https://orcid.org/0000-0001-7718-5953

\section{REFERENCES}

Adler, Paul S., and Bryan Borys. 1996. "Two Types of Bureaucracy: Enabling and Coercive.” Administrative Science Quarterly 41(1): 61-89.

Aiken, Leona S., and Stephen G. West. 1991. Multiple Regression: Testing and Interpreting Interactions. Thousand Oaks, CA: Sage Publications Inc.

Appio, Francesco Paolo, Federico Frattini, Antonio Messeni Petruzzelli, and Paolo Neirotti. 2021. "Digital Transformation and Innovation Management: A Synthesis of Existing Research and an Agenda for Future Studies." Journal of Product Innovation Management 38(1): 4-20.

Aroles, Jeremy, and Christine McLean. 2016. "Rethinking Stability and Change in the Study of Organizational Routines: Difference and Repetition in a Newspaper-Printing Factory." Organization Science 27(3): 535-50.

Bagozzi, Richard P., and Youjae Yi. 2012. "Specification, Evaluation, and Interpretation of Structural Equation Models." Journal of the Academy of Marketing Science 40(1): 8-34.

Baur, Cornelius, and Dominik Wee. 2015. Manufacturing's Next Act. Munich: McKinsey Company.

Bharadwaj, Anandhi, Omar A. El Sawy, Paul A. Pavlou, and N. Venkatraman. 2013. "Digital Business Strategy: Toward a Next Generation of Insights.” MIS Quarterly 37(2): 471-82. 
Bouncken, Ricarda, and Roman Barwinski. 2021. "Shared Digital Identity and Rich Knowledge Ties in Global 3D Printing-A Drizzle in the Clouds?" Global Strategy Journal 11(1): 81-108.

Bouncken, Ricarda B., and Sascha Kraus. 2013. "Innovation in Knowledge-Intensive Industries: The Double-Edged Sword of Coopetition." Journal of Business Research 66(10): 2060-70.

Bourgoin, Alaric, Nicolas Bencherki, and Samer Faraj. 2020. ““'And Who Are You?": A Performative Perspective on Authority in Organizations." Academy of Management Journal 63(4): 1134-65.

Briscoe, Forrest. 2007. "From Iron Cage to Iron Shield? How Bureaucracy Enables Temporal Flexibility for Professional Service Workers." Organization Science 18(2): 297-314.

Burns, Tom, and George Stalker. 1961. The Management of Innovation. London: Tavistock.

Cabanes, Jean, Aidan Quilligan, Raghav Narsalay, and Aarohi Sen. (2019). Manufacturing Growth with Digital Innovation. Paris: Accenture.

Cappa, Francesco, Raffaele Oriani, Enzo Peruffo, and Ian McCarthy. 2020. "Big Data for Creating and Capturing Value in the Digitalized Environment: Unpacking the Effects of Volume, Variety and Veracity on Firm Performance." Journal of Product Innovation Management 38(1): 49-67.

Cardinal, Laura B. 2001. "Technological Innovation in the Pharmaceutical Industry: The Use of Organizational Control in Managing Research and Development." Organization Science 12(1): 19-36.

Chadwick, Clint, Janice F. Super, and Kiwook Kwon. 2015. "Resource Orchestration in Practice: CEO Emphasis on SHRM, Commitment-Based HR Systems, and Firm Performance." Strategic Management Journal 36(3): 360-76.

Christiansen, John K., and Claus J. Varnes. 2009. "Formal Rules in Product Development: Sensemaking of Structured Approaches." Journal of Product Innovation Management 26(5): 502-19.

Coad, Alex, Agustí Segarra, and Mercedes Teruel. 2016. "Innovation and Firm Growth: Does Firm Age Play a Role?” Research Policy 45(2): 387-400.

Cohen, Jacob, Patricia Cohen, Stephen G. West, and Leona S. Aiken. 2003. Applied Multiple Regression/Correlation Analysis for the Behavioral Sciences. Mahwah, NJ: Lawrence Erlbaum Associates.

Damanpour, Fariborz. 1991. "Organizational Innovation: A MetaAnalysis of Effects of Determinants and Moderators.” Academy of Management Journal 34(3): 555-90.

De Meyer, Arnoud Cyriel Leo, Cyriel H. Loch, and Michael T. Pich. 2002. "Managing Project Uncertainty: From Variation to Chaos." MIT Sloan Management Review 43(2): 60-7.

Deshpandé, Rohit, John U. Farley, and Frederick E. Webster, Jr. 1993. "Corporate Culture, Customer Orientation, and Innovativeness in Japanese Firms: A Quadrad Analysis.” Journal of Marketing 57(1): 23-37.

Dhanaraj, C., and P. W. Beamish. 2004. "Effect of Equity Ownership on the Survival of International Joint Ventures.” Strategic Management Journal 25(3): 295-305.

Dobusch, L., L. Dobusch, and G. Müller-Seitz. 2019. "Closing for the Benefit of Openness? The Case of Wikimedia's Open Strategy Process." Organization Studies 40(3): 343-70.

Dönmez, Denniz, Gudela Grote, and Stefano Brusoni. 2016. "Routine Interdependencies as a Source of Stability and Flexibility. A
Study of Agile Software Development Teams." Information and Organization 26(3), 63-83.

Dougherty, Deborah. 1992. "Interpretive Barriers to Successful Product Innovation in Large Firms." Organization Science 3(2): 179-202.

Dougherty, Deborah, Leslie Borrelli, Kamal Munir, and Alan O'Sullivan. 2000. "Systems of Organizational Sensemaking for Sustained Product Innovation." Journal of Engineering and Technology Management 17(3): 321-55.

Dougherty, Deborah, and Cynthia Hardy. 1996. "Sustained Product Innovation in Large, Mature Organizations: Overcoming Innovation-to-Organization Problems." Academy of Management Journal 39(5): 1120-53.

Dul, Jan, and Canan Ceylan. 2014. "The Impact of a CreativitySupporting Work Environment on a Firm's Product Innovation Performance." Journal of Product Innovation Management 31(6): 1254-67.

Dziallas, Marisa, and Knut Blind. 2019. "Innovation Indicators Throughout the Innovation Process: An Extensive Literature Analysis." Technovation 80-81: 3-29.

Endres, Herbert, Stefan Huesig, and Robin Pesch. 2021. "Digital Innovation Management for Entrepreneurial Ecosystems: Services and Functionalities as Drivers of Innovation Management Software Adoption.” Review of Managerial Science 1-22. https://doi.org/10.1007/s11846-021-00441-4.

Endres, H., M. Indulska, A. Ghosh, A. Baiyere, and S. Broser. 2019. "Industrial Internet of Things (IIoT) Business Model Classification." In 40th International Conference on Information Systems. ICIS 2019 Association for Information Systems, 2988. AIS Electronic Library (AISeL).

Farjoun, Moshe. 2010. "Beyond Dualism: Stability and Change as Duality." Academy of Management Review 35(2): 202-25.

Fichman, Robert G., Brian L. Dos Santos, and Zhiqiang (Eric) Zheng. 2014. "Digital Innovation as a Fundamental and Powerful Concept in the Information Systems Curriculum.” MIS Quarterly 38(2): 329-43.

Flores, Luis G., Wei Zheng, Devaki Rau, and Christopher H. Thomas. 2012. "Organizational Learning: Subprocess Identification, Construct Validation, and an Empirical Test of Cultural Antecedents." Journal of Management 38(2): 640-67.

Fornell, Claes, and David F. Larcker. 1981. "Structural Equation Models with Unobservable Variables and Measurement Error-Algebra and Statistics." Journal of Marketing Research 18(3): 382-8.

Garcia, Rosanna, and Roger Calantone. 2002. "A Critical Look at Technological Innovation Typology and Innovativeness Terminology: A Literature Review." Journal of Product Innovation Management 19(2): 110-32.

Gioia, Dennis A., and Kumar Chittipeddi. 1991. "Sensemaking and Sensegiving in Strategic Change Initiation.” Strategic Management Journal 12(6): 433-48.

Haans, Richard F. J., Constant Pieters, and Zi-Lin He. 2016. "Thinking About U: Theorizing and Testing U-and Inverted U-Shaped Relationships in Strategy Research.” Strategic Management Journal 37(7): 1177-95.

Hannan, Michael T., and John Freeman. 1984. "Structural Inertia and Organizational Change." American Sociological Review 49(2): 149-64. 
Heid, Bernd, Dago Diedrich, Matthias Kässer, and Sebastian Küchler. 2018. Route 2030-The Fast Track to the Future of the Commercial Vehicle Industry. Munich: McKinsey Center for Future Mobility.

Henfridsson, Ola, Joe Nandhakumar, Harry Scarbrough, and Nikiforos Panourgias. 2018. "Recombination in the OpenEnded Value Landscape of Digital Innovation." Information and Organization 28(2): 89-100.

Hill, Charles W. L., and Frank T. Rothaermel. 2003. “The Performance of Incumbent Firms in the Face of Radical Technological Innovation." The Academy of Management Review 28(2): 257-74.

Hopp, Christian, David Antons, Jermain Kaminski, and Torsten Oliver Salge. 2018. "Disruptive Innovation: Conceptual Foundations, Empirical Evidence, and Research Opportunities in the Digital Age." Journal of Product Innovation Management 35(3): 446-57.

Huesig, Stefan, and Herbert Endres. 2019. "Exploring the Digital Innovation Process." European Journal of Innovation Management 22(2): 302-14. https://doi.org/10.1108/EJIM-02-2018-0051

Hwang, Hokyu, and Walter W. Powell. 2009. "The Rationalization of Charity: The Influences of Professionalism in the Nonprofit Sector.” Administrative Science Quarterly 54(2): 268-98.

Ivanov, Milen. 2020. "Digital Innovation in Manufacturing Firms: Why Smart Connected Products Become a Challenge?" In ICT for an Inclusive World: Industry 4.0-Towards the Smart Enterprise, edited by Youcef Baghdadi, Antoine Harfouche and Marta Musso, 581-90. Cham: Springer International Publishing.

Jansen, Justin J. P., Frans A. J. Van Den Bosch, and Henk W. Volberda. 2006. "Exploratory Innovation, Exploitative Innovation, and Performance: Effects of Organizational Antecedents and Environmental Moderators." Management Science 52(11): 1661-74.

Juillerat, Tina L. 2010. "Friends, Not Foes? Work Design and Formalization in the Modern Work Context." Journal of Organizational Behavior 31(2-3): 216-39.

Kaplan, Sarah, and Mary Tripsas. 2008. "Thinking About Technology: Applying a Cognitive Lens to Technical Change." Research Policy 37(5): 790-805.

Katz, Daniel, and Robert L. Kahn. 1966. The Social Psychology of Organizing. New York: Wiley.

Kellogg, Katherine C., Wanda J. Orlikowski, and Jo Anne Yates. 2006. "Life in the Trading Zone: Structuring Coordination Across Boundaries in Postbureaucratic Organizations." Organization Science 17(1): 22-44.

Kohli, Rajiv, and Nigel P. Melville. 2019. "Digital Innovation: A Review and Synthesis." Information Systems Journal 29(1): 200-23.

Lange, Oliver. 2017. "Chancen und Risiken der Digitalisierung." PLASTVERARBEITER https://www.plastverarbeiter.de/ automation/chancen-und-risiken-der-digitalisierung.html.

Lanzolla, Gianvito, Danilo Pesce, and Christopher L. Tucci. 2021. "The Digital Transformation of Search and Recombination in the Innovation Function: Tensions and an Integrative Framework." Journal of Product Innovation Management 38(1): 90-113.

Lindell, Michael K., and David J. Whitney. 2001. “Accounting for Common Method Variance in Cross-Sectional Research Designs.” Journal of Applied Psychology 86(1): 114-21.
Loch, Christoph H., Arnoud De Meyer, and Michael T. Pich. 2006. Managing the Unknown. Hoboken, NJ: Wiley.

Loebbecke, Claudia, and Arnold Picot. 2015. "Reflections on Societal and Business Model Transformation Arising from Digitization and Big Data Analytics: A Research Agenda." The Journal of Strategic Information Systems 24(3): 149-57.

Lyytinen, Kalle, Youngjin Yoo, and Richard J. Boland, Jr. 2016. "Digital Product Innovation Within Four Classes of Innovation Networks." Information Systems Journal 26(1): $47-75$.

MacCallum, Robert C., Keith F. Widaman, Shaobo Zhang, and Sehee Hong. 1999. "Sample Size in Factor Analysis." Psychological Methods 4: 84-99.

Majumdar, Sumit K. 1997. "The Impact of Size and Age on FirmLevel Performance: Some Evidence from India." Review of Industrial Organization 12(2): 231-41.

Malhotra, Arvind, and Ann Majchrzak. 2021. "Hidden Patterns of Knowledge Evolution in Fluid Digital Innovation.” Innovation 1-12. Online first.

March, James G., and Herbert Simon. 1958. Organizations. Oxford: Blackwell.

Marion, Tucker J., and Sebastian K. Fixson. 2021. "The Transformation of the Innovation Process: How Digital Tools are Changing Work, Collaboration, and Organizations in New Product Development.” Journal of Product Innovation Management 38(1): 192-215.

Martela, Frank. 2019. "What Makes Self-Managing Organizations Novel? Comparing How Weberian Bureaucracy, Mintzberg's Adhocracy, and Self-Organizing Solve Six Fundamental Problems of Organizing." Journal of Organization Design 8(1): 23.

Matt, Christian, Thomas Hess, and Alexander Benlian. 2015. "Digital Transformation Strategies." Business \& Information Systems Engineering 57(5): 339-43.

Ménière, Yann, Iija Rudyk, and Javier Valdes. 2017. Patents and the Fourth Industrial Revolution. The Inventions Behind Digital Transformation. Munich: European Patent Office.

Milliken, Frances J. 1987. “Three Types of Perceived Uncertainty About the Environment: State, Effect, and Response Uncertainty." Academy of Management Review 12(1): 133-43.

Mintzberg, Henry. 1994. The Rise and Fall of Strategic Planning. Hemel Hempstead: Prentice Hall.

Mintzberg, Henry, and Alexandra McHugh. 1985. "Strategy Formation in an Adhocracy." Administrative Science Quarterly 30(2): 160-97.

Monaghan, Sinéad, Esther Tippmann, and Nicole Coviello. 2020. "Born Digitals: Thoughts on their Internationalization and a Research Agenda.” Journal of International Business Studies 51(1): 11-22.

Moore, Elizabeth M., Luis Alfonso Dau, and Santiago Mingo. 2021. "The Effects of trade integration on Formal and Informal Entrepreneurship: The Moderating Role of Economic Development.” Journal of International Business Studies 52(4): 746-772.

Munuera, Luis. 2020. Smart Grids. Paris: IEA.

Nambisan, Satish, Kalle Lyytinen, Ann Majchrzak, and Michael Song. 2017. "Digital Innovation Management: Reinventing Innovation Management Research in a Digital World." MIS Quarterly 41(1): 223-38. 
Noble, Charles H., and Jelena Spanjol. 2019. "Opening Thoughts from the New Editors." Journal of Product Innovation Management 36(1): 2-4.

Nwankpa, Joseph K., and Pratim Datta. 2017. "Balancing Exploration and Exploitation of IT Resources: The Influence of Digital Business Intensity on Perceived Organizational Performance." European Journal of Information Systems 26(5): 469-88.

Nylén, Daniel, and Jonny Holmström. 2015. "Digital Innovation Strategy: A Framework for Diagnosing and Improving Digital Product and Service Innovation.” Business Horizons 58(1): 57-67.

Organ, Dennis W., and Charles N. Greene. 1981. "The Effects of Formalization on Professional Involvement: A Compensatory Process Approach.” Administrative Science Quarterly 26(2): 237-52.

Orlikowski, Wanda J., and Debra C. Gash. 1994. “Technological Frames: Making Sense of Information Technology in Organizations." ACM Transactions on Information Systems 12(2): 174-207.

Ouchi, William G. 1979. "A Conceptual Framework for the Design of Organizational Control Mechanisms.” Management Science 25(9): 833-48.

Pesch, Robin, and Ricarda B. Bouncken. 2017. "The DoubleEdged Sword of Cultural Distance in International Alliances: How Perceived Cultural Distance Influences Trust and Task Discourse to Drive New Product Development Performance." Cross Cultural \& Strategic Management 24(1): 33-54.

Ramus, Tommaso, Antonino Vaccaro, and Stefano Brusoni. 2017. "Institutional Complexity in Turbulent Times: Formalization, Collaboration, and the Emergence of Blended Logics." Academy of Management Journal 60(4): 1253-84.

Rindfleisch, Aric, Matthew O'Hern, and Vishal Sachdev. 2017. "The Digital Revolution, 3D Printing, and Innovation as Data." Journal of Product Innovation Management 34(5): 681-90.

Schaller, Tracey King, Ashutosh Patil, and Naresh K. Malhotra. 2015. “Alternative Techniques for Assessing Common Method Variance: An Analysis of the Theory of Planned Behavior Research." Organizational Research Methods 18(2): 177-206.

Schoeneborn, Dennis, Timothy R. Kuhn, and Dan Kärreman. 2018. "The Communicative Constitution of Organization, Organizing, and Organizationality.” Organization Studies 40(4): 475-96.

Schreyögg, Georg, and Jörg Sydow. 2010. "Crossroads-Organizing for Fluidity? Dilemmas of New Organizational Forms." Organization Science 21(6): 1251-62.

Schultz, Carsten, Søren Salomo, Ulrike de Brentani, and Elko J. Kleinschmidt. 2013. "How Formal Control Influences DecisionMaking Clarity and Innovation Performance.” Journal of Product Innovation Management 30(3): 430-47.

Scott, W. Richard, and Gerald F. Davis. 2006. Organizations and Organizing: Rational, Natural and Open Systems Perspectives. Upper Saddle River, NJ: Pentrice Hall.

Shimizu, Katsuhiko, and Michael A. Hitt. 2005. "What Constrains or Facilitates Divestitures of Formerly Acquired Firms? The Effects of Organizational Inertia." Journal of Management 31(1): 50-72.
Siemsen, Enno, Aleda Roth, and Pedro Oliveira. 2010. "Common Method Bias in Regression Models with Linear, Quadratic, and Interaction Effects.” Organizational Research Methods 13(3): 456-76.

Sine, Wesley D., Hitoshi Mitsuhashi, and David A. Kirsch. 2006. "Revisiting Burns and Stalker: Formal Structure and New Venture Performance in Emerging Economic Sectors." Academy of Management Journal 49(1): 121-32.

Spanjol, J., Y. Xiao, and L. Welzenbach. 2018. "Successive Innovation in Digital and Physical Products: Synthesis, Conceptual Framework, and Research Directions." In Innovation and Strategy, edited by Rajan Varadarajan and Satish Jayachandran, 31-62. Bingley: Emerald Publishing.

Svahn, Fredrik, Lars Mathiassen, and Rikard Lindgren. 2017. "Embracing Digital Innovation in Incumbent Firms: How VOLVO Cars Manages Competing Concerns.” MIS Quarterly 41(1): 234-53.

Tatikonda, Mohan V., and Mitzi M. Montoya-Weiss. 2001. "Integrating Operations and Marketing Perspectives of Product Innovation: The Influence of Organizational Process Factors and Capabilities on Development Performance." Management Science 47(1): 151-72.

Teller, Juliane, Barbara Natalie Unger, Alexander Kock, and Hans Georg Gemünden. 2012. "Formalization of Project Portfolio Management: The Moderating Role of Project Portfolio Complexity." International Journal of Project Management 30(5): 596-607.

Verganti, Roberto, Luca Vendraminelli, and Marco Iansiti. 2020. "Innovation and Design in the Age of Artificial Intelligence." Journal of Product Innovation Management 37(3): 212-27.

Vial, Gregory. 2019. "Understanding Digital Transformation: A Review and a Research Agenda." The Journal of Strategic Information Systems 28(2): 118-44.

Vlaar, Paul W. L., Frans A. J. Van den Bosch, and Henk W. Volberda. 2006. "Coping with Problems of Understanding in Interorganizational Relationships: Using Formalization as a Means to Make Sense." Organization Studies 27(11): 1617-38.

Walsh, James P., and Robert D. Dewar. 1987. "Formalization and the Organizational Life Cycle.” Journal of Management Studies 24(3): 215-31.

Weber, Max. 1947. The Theory of Social and Economic Organization. New York: The Free Press.

Bodewes, Wynand E. J. 2002. "Formalization and Innovation Revisited.” European Journal of Innovation Management 5(4): 214-23.

Yoo, Youngjin, Richard J. Boland, Jr., Kalle Lyytinen, and Ann Majchrzak. 2012. "Organizing for Innovation in the Digitized World.” Organization Science 23(5): 1398-408.

Yoo, Youngjin, Ola Henfridsson, and Kalle Lyytinen. 2010. “The New Organizing Logic of Digital Innovation: An Agenda for Information Systems Research.” Information Systems Research 21(4): 724-35.

Zmud, Robert W. 1982. "Diffusion of Modern Software Practices: Influence of Centralization and Formalization.” Management Science 28(12): 1421-31. 


\section{AUTHOR BIOGRAPHIES}

Robin Pesch is Senior Lecturer in International Management and Degree Programme Director in International Business Management at Newcastle University Business School. He holds a PhD in Business Administration from the University of Bayreuth, Germany. His research concentrates on global innovation alliances, digital innovation and transformation, and cross-cultural management. Robin has published in leading international journals such as the Global Strategy Journal, Journal of Business Research, and British Journal of Management.

Herbert Endres is Visiting Professor of Marketing \& Innovation Management, University of Paderborn, Germany. He holds an MBA from the MSU, USA and a Diploma and a PhD in Business Administration from the University of Regensburg, Germany. Before Herbert Endres started his PhD, he had worked in leadership positions in marketing and innovation management in the industry for several years (e.g., for Nestlé SA). He has published in leading international journals such as the Industrial Marketing Management and regularly presents at the most renowned international conferences. His recent research covers marketing intelligence, (digital) transformation management, sensing market opportunities and threats, marketing analytics, and digital innovation management.

Ricarda B. Bouncken is Distinguished Professor of Strategic Management and Organization, University of Bayreuth, Germany. Her research centers on how innovation within and among firms can be improved through strategic and organizational arrangements. In this vein she researches collaborative work-spaces among start-ups, corporates, and freelancers, partly as corporate venturing. Recent research covers digital innovation and its organizational underpinnings, e.g., organizational digital identity and digital empowerment. She is Associate Editor of the European Management Journal and the Review of Managerial Science and member of several review boards. She has published more than 200 articles, e.g., in the Journal of Service Research, Journal of Business Research, Long Range Planning, British Journal of Management, Global Strategy Journal and the Academy of Management Journal.
How to cite this article: Pesch, Robin, Herbert Endres, and Ricarda B. Bouncken. 2021. "Digital Product Innovation Management: Balancing Stability and Fluidity Through Formalization." Journal of Product Innovation Management 00: 1-19. https://doi.org/10.1111/jpim.12609

\section{APPENDIX A}

\section{Latent constructs}

Notes: All latent constructs are measured on 5-point Likert scales $(1=$ totally disagree; $5=$ totally agree $) . \mathrm{CR}=$ composite reliability, AVE = average variance extracted.

Formalization $(\mathrm{CR}=0.96, \mathrm{AVE}=0.89)$

1. Core processes to build digitalization projects are strongly formalized within our company.

2. Core processes to accomplish digitalization projects are strongly formalized within our company.

3. Core processes to monitor digitalization projects are strongly formalized within our company.

Relative digital product innovation performance $(\mathrm{CR}=0.93, \mathrm{AVE}=0.83)$

1. Our digital product innovations achieve a greater success rate relative to our competitors.

2. Our digital product innovations achieve greater revenue relative to our competitors.

3. Our digital product innovations achieve greater profitability relative to our competitors.

Digital product innovation radicalness $(C R=0.92$, AVE $=0.79$ )

1. Our digital products are breakthrough innovations.

2. Our digital products are technological advancements that make old technologies obsolete.

3. Our digital products deliver completely new benefits to customers. 